\title{
Los ecos indianos del gran levantamiento de Tupac Amaru y su proyección peninsular: un episodio olvidado*
}

por

Alfredo Moreno Cebrián ${ }^{1}$

Instituto de Historia-CSIC
Jorge Chauca García ${ }^{2}$

Universidad de Málaga

El movimiento rebelde encabezado por Tupac Amaru II entre 1780 y 1781 no se circunscribió a unas coordenadas espacio-temporales demarcadas por su repercusión en el escenario peruano y altoperuano. En este trabajo analizamos el tortuoso itinerario seguido por los prisioneros tupamaristas tanto en su paso por Chile como en su destino final en España. En el caso chileno se incidirá en el temor que entre las autoridades provocó la presencia temporal de estos reos sobre todo como posible contagio social. En lo que se refiere a los escasos reos tupamaristas que sobrevivieron a los naufragios de los navios San Pedro de Alcántara y El Peruano y llegaron a España, se centrará la atención en sus trayectorias hasta que fueron confinados en los presidios norteafricanos.

Palabras Clave: Perú; Chile; España; Tupac Amaru II; destierro; naufragio.

Cómo Citar este artículo / Citation: Moreno Cebrián, Alfredo y Chauca García, Jorge, "Los ecos indianos del gran levantamiento de Tupac Amaru y su proyección peninsular: un episodio olvidado", Revista de Indias, LXXX/279 (Madrid, 2020): 317-344. https://doi. org/10.3989/revindias.2020.009.

Queda fuera de toda duda la relevancia del levantamiento de Tupac Amaru II para la historia del Perú y el mundo hispánico. En consecuencia,

* El presente artículo forma parte del proyecto de investigación I+D+i Retos "Cambios e innovaciones sociales: España y el Perú de la crisis del imperio transoceánico al Estado liberal" (Referencia: HAR2015-67197-R) del Instituto de Historia del CSIC (investigador principal: Alfredo Moreno Cebrián). Igualmente es fruto de la estancia de investigación financiada al Dr. Chauca García en el Instituto de Estudios Peruanos (IEP) de Lima en 2016.

1 alfredo.moreno@cchs.csic.es, ORCID iD: https://orcid.org/0000-0002-5170-7415

2 chauca@uma.es, ORCID iD: https://orcid.org/0000-0003-4804-3459 
no resulta extraña la abundante bibliografía sobre el tema, así como los debates originados y polémicas suscitadas. De ello da testimonio fehaciente el estado actual de la investigación sobre su figura y el complejo proceso que acaudilló, en sus causas y razones, si bien las consecuencias han sido relegadas a meros epílogos subsidiarios. El interés por el carácter político del movimiento andino, en sus versiones tanto clásicas como actualizadas, ha conducido a privilegiar el contenido ideológico sobre el programa económico (lucha contra los repartos de mercancías, la mita y el tributo) a la luz de corrientes de investigación que tienen como "lugares comunes" la disidencia por encima del malestar. Alberto Flores Galindo al intitular uno de sus trabajos bajo la denominación de revolución tupamarista formuló un alegato al componente nacionalista indígena de sus huestes y a la "inversión del mundo" en todos los aspectos sociales que hubiera supuesto el éxito de su proyecto utópico ${ }^{3}$.

No es propósito de este trabajo participar en la polémica anterior ni ofrecer un balance historiográfico ${ }^{4}$. Nos interesa más bien resaltar las repercusiones de la rebelión tupamarista más allá de las fronteras del virreinato peruano ${ }^{5}$. Una serie de investigaciones han discutido dicha proyección en el virreinato del Río de la Plata. Concretamente, se destacan las resonancias del levantamiento cuzqueño en las rebeliones indígenas de la Audiencia de Charcas en $1781^{6}$. Estas repercusiones de la rebelión tupamarista no excluyeron a Chile y su frontera araucana porque incluso el septentrión chileno se resintió ${ }^{7}$. A la luz de lo anterior, nuestro estudio se centrará en la posible inquietud provocada por la presencia de los familiares de Tupac Amaru en Chile y en España. En este sentido, nos planteamos dos hipótesis de trabajo. La primera hipótesis se propone demostrar por qué la presencia de los reos tupamaristas en el navío español "San Pedro de Alcántara", a pesar del "gran miedo" expresado por las autoridades locales, no se constituyó en una real amenaza que pudiese provocar un levantamiento entre los indígenas del Chile meridional. La segunda hipótesis argumenta que los dos familiares más significativos de Tupac Amaru que finalmente fueron confinados en los presidios norteafricanos, Juan Bautista y Fernando, se abstuvieron de promover simpatía alguna hacia la causa tupamarista en la Península Ibérica.

\footnotetext{
3 Flores Galindo, 2015 [1986]: 109-138.

4 Serulnikov, 2010 y 2012.

5 Eguiguren, 1952: 68-71. Lewin, 1957 y 1982.

6 Valle de Siles, 1990. O’Phelan, 1995. Cajías, 1982 y 2004. Thomson, 2006. Serulnikov, 2006 y 2007.

7 Villalobos, 1982.
} 


\section{REPERCUSIONES DE LA AGITACIÓN ANDINA EN EL CHILE MERIDIONAL}

Ambrosio Higgins tranquilizaba al secretario de Indias José de Gálvez en misiva fechada a finales septiembre de 1781 sobre los posibles ecos de la rebelión. Protegido de este poderoso ministro, el irlandés ascendió vertiginosamente a los puestos de capitán graduado de dragones (1770), capitán de caballería (1771), teniente coronel y comandante de caballería (1773), maestre de campo interino (1776), coronel y maestre de campo general (1777) y brigadier (1785). Las campañas contra los araucanos, en las cuales participó activamente desde su llegada a Chile, le proporcionaron "honra y provecho" y explican su vertiginoso ascenso como servidor del rey ${ }^{8}$. Higgins, en la referida carta de 1781, prometió a su mentor Gálvez que emprendería su acostumbrada visita fronteriza anual para mantener la quietud: «Prometo con toda confianza de que por estos lados no habrá movimiento sensible» ${ }^{9}$. No sería la única ocasión que iba a tener para enfrentarse desde el meridión a la proyección de la magna revuelta, ni la primera vez en transmitir la paz reinante al ministro malagueño.

Higgins, en su condición de comandante de caballería de la frontera, se ufanaba de haber cortado la tentativa rebelde del cacique o lonco mapuche Chicaguala en el poblado de Repocura cuando aún ejercía de capitán general Agustín de Jáuregui. Este indio con ayuda había planeado a imitación del líder cuzqueño provocar la insurrección fronteriza, abortada sin despertar excesivo ruido y evitando derramamiento de sangre ${ }^{10}$. Si los movimientos rebeldes del altiplano peruano ofrecieron la posibilidad de ascenso en recompensa a la fidelidad de los que los combatieron, la frontera de Chile había sido también teatro de este tipo de tentativas que derivaron en promoción de quienes participaron en su contención. De hecho, Jáuregui una vez ascendido a virrey del Perú recomendó a Higgins ante el ministro de Indias, merced a sus méritos y servicios militares ${ }^{11}$. De esta manera, Higgins supo acumular padrinos metropolitanos e indianos, así como premios, tanto por su actuación fronteriza en la cuestión indígena, como en la distancia por las precauciones tomadas frente a la propagación de la llama insurreccional.

8 Chauca García, 2016.

9 Valcárcel, 1996: 214.

10 Carta de Ambrosio Higgins a José de Gálvez, 25 de noviembre de 1781, Archivo General de Indias, Sevilla (AGI), Lima, legajo 1040. Citado por Valcárcel, 1970: 302-303. Véase Roel Pineda, 1988: 57-58.

11 Carta $n^{\circ} 254$ de Agustín de Jáuregui, virrey del Perú, a José de Gálvez, secretario de Indias, 16 de agosto de 1783, AGI, Lima, legajo 663, N. 29. 
Gestionar con «acertadas y prontas providencias [...] con la correspondiente severidad, para que no quede consentido un delito de esta naturaleza, y tan malas consecuencias», resultaba una política estimulada por la Corona española frente a las rebeliones, como confesaba abiertamente en tono laudatorio el ministro Gálvez a Andrés Mestre desde El Pardo el 12 de enero de 1782 ${ }^{12}$. El gobernador Mestre tranquilizó la provincia del Tucumán siguiendo dichas recomendaciones con una represión feroz del alzamiento toba de 1781, por lo cual sería su primer intendente tras la reforma de 1782, cargo al que accedió un año después ${ }^{13}$. Hombre de frontera, Mestre tuvo que hacer frente a la extensión de la revuelta peruana y durante su gobernación vio interrumpido el comercio con el norte ${ }^{14}$. La importancia del conocimiento de los hechos y la circulación de ideas en un dilatado imperio, en el cual las colosales distancias suponían un perenne obstáculo a salvar, era cuestión clave para la optimización administrativa y el efectivo control territorial e ideológico. Asegurar y agilizar los cauces de transmisión de la información se presentaban como méritos de un buen gobierno en el campo político.

Las tranquilizadoras noticias transmitidas por Higgins a Gálvez sobre la quietud del territorio austral bajo su mando, en el contexto de un pánico que recorría los Andes por obra de Tupac Amaru, fueron un aldabonazo más en su eficiente carrera y cimiento de su ascenso personal. Incluso este comandante general de la frontera chilena aprovechó la misiva a Gálvez para remitirle noticias sobre el curso de la guerra en las cercanías del Cuzco. Estas novedades le habían llegado por medio de una embarcación que arribó a Concepción desde El Callao y, concretamente, a través de una carta remitida al obispo local. A su vez, por si no había recibido con anterioridad dicho aviso, por otros conductos se la enviaba en un alarde de clientelismo meritocrático $^{15}$. Sin embargo, la alarma que recorría las tierras sudamericanas no era baladí. Muy al contrario, la proyección del gran levantamiento alcanzó a distantes regiones, incluidas las fronteras chilenas, de ahí los temores hispanos al respecto desde Buenos Aires y la necesaria toma de medidas de contención:

Que la multitud de Yndios infieles que residen en el Chaco se hallava en movimiento, preparandose de flechas, y demas Armas de su uso para salir a defender a su Rey Inca que los llama. Lo mismo escriven de Chile de los Aucaes, Peguenches, y demas naciones barbaras que residen por aquellas partes, los que venian a

12 Cornejo Bouroncle, 2013 [1949]: 393-394.

13 Lorandi, 2008: 180.

14 Gullón Abao, 1993: 113.

15 Carta de Ambrosio Higgins al ministro de Indias José de Gálvez, 13 de abril de 1781. En Valcárcel, 1971: 646-648. 
unirse con los Pampas de Buenos Ayres para acometerla. En estos terminos la rebelion va estendiendose y si Dios no se apiada, estamos muy expuestos a ser victima de su furor ${ }^{16}$.

El edicto de coronación como inca rey que se encontró en la faltriquera de Tupac Amaru cuando fue capturado, fechado en Tungusaca el 18 de marzo de 1781, lo presentaba como «Don Josef primero por la gracia de Dios Ynga Rey del Peru, Santa Fe, Quito, Chile, Buenos Ayres y Continentes de los Mares del Sur, Duque de la Superlativa, Señor de los Cesares y Amazonas con Dominio en el gran Paititi ${ }^{17}$. Se autodeclaraba Inca, con lo que reivindicaba todos los antiguos territorios del Tahuantinsuyo, además de ampliar su soberanía continental y allende los mares, en memoria de la legendaria expedición oceánica de Tupac Yupanqui ${ }^{18}$. Aparte de su ascendencia como elemento legitimador ${ }^{19}$, la tradición reclamada por entonces era fruto de una hibridación ${ }^{20}$. Pero lo más llamativo era la validación que hacía como señor natural de espacios míticos. No quedaba fuera de su imperio imaginario la frontera austral y su fabulosa ciudad oculta desde tiempo lejano en la región patagónica ${ }^{21}$. Resulta imprescindible señalar que, de acuerdo con la historiografía especializada, se trata de un documento apócrifo o en cualquier caso de dudosa autoría. Pero, siguiendo a Bonilla, por encima de su discutida autenticidad, «más allá de los propósitos conscientes o no, de las declaraciones o silencios, es la textura de los acontecimientos la que brinda respuestas más firmes» ${ }^{22}$.

Una vez concluida la primera fase bélica en el sur peruano y en el Alto Perú operó un segundo eco enhebrado por el paso de los prisioneros cuzqueños por las latitudes extremas de Chile. A finales de 1784, el virrey del Perú Teodoro de Croix comunicaba a Gálvez los pormenores acaecidos a los reos pertenecientes o vinculados a la familia de Tupac Amaru conducidos a España desde El Callao. Su predecesor, Agustín de Jáuregui, había notificado el 1

16 Extracto, y recopilacion de las noticias mas veridicas, que se han podido adquirir sobre lo ocurrido desde el 4 de Noviembre de 1780 en el Plan formado por el iniquo rebelde cazique de la Provincia de Tinta Josef Gabriel Tupac Amaru, y sublevacion general del Reino del Perú, que ha sucitado contra nuestro catolico Monarca, y sus fieles (Europeos) vasallos, 21 de abril de 1781, Real Academia de la Historia, América, Papeles varios, sig. 9/4161, fol. $111 \mathrm{v}$.

17 Valcárcel, 1971: 578-579.

18 Busto Duthurburu, 2000.

19 Loayza, 1946: 5-59.

20 Faverón Patriau, 2006: 214.

21 Gutiérrez Escudero, 2006: 213. Durand Flores, 1973.

22 Bonilla, 2001: 88. 
de abril anterior dicha salida en los navíos de guerra "El Peruano" y "San Pedro de Alcántara". No obstante, según informaba el nuevo virrey, la lista oficial había experimentado modificaciones en el intermedio, bien por fallecimiento o enfermedad de algunos de sus integrantes. Finalmente, entre ambos buques del rey comprendían sesenta y nueve, incluidos dos franceses de Chile y un insumiso militar español añadido a la compilación por equivocación. La desventurada arribada del segundo navío al puerto chileno de Talcahuano en Concepción, donde por obra del maestre de campo Higgins entraron en cuarentena política por temor al contagio revolucionario, obligó a informar sobre el número de reos embarcados en dicho accidentado buque. Cuarenta en total según la relación de fecha 13 de abril de 1784, es decir, la mayoría de la remesa, de los cuales veinticuatro eran hombres y dieciséis mujeres (cuadro 1).

Cuadro 1. Relación de indíGenas Conducidos Por el Navío "San Pedro de Alcántara” (Primera salida, El Callao a 13 de abril de 1784)

\begin{tabular}{|l|l|}
\hline \multicolumn{1}{|c|}{ Hombres (24) } & \multicolumn{1}{c|}{ Mujeres (16) } \\
\hline Fernando Condorcanqui & Ascencia Fuentes Castro \\
Andrés Mendigure & Francisca de Fuentes Castro \\
Manuel Silvestre Rojas & Manuela Tito Condori \\
Nicolás Almendras & Santusa Castro \\
Juan Tomás Palomino & Paula Castro \\
Juan Barrientos & Margarita Noguera \\
Ignacio Quispe & María Luque \\
Pablo Quispe & Paula Noguera \\
Melchor Ramos & Felipa Mendigure \\
Crispín Guaman & Lorenza Mendigure \\
Antonio Camaque & Patricia Díaz \\
Blas Guaman & Bartola Escovedo \\
Marcelo Luque & Nicolasa Aguirre \\
Silvestre Luque & Antonia Caya \\
Lorenzo Noguera & Santusa Canqui \\
Ambrosio Mendigure & Antonia Castro \\
Mariano Mendigure & \\
Pedro Venero & \\
Antolin Ortiz & \\
Antonio Castro & \\
Dos hijos Franciscos & \\
José de Castro & \\
Antonio Alejandro Bergni (francés) & \\
[sic Berney] & \\
\hline
\end{tabular}

Fuente: AGI, Lima, legajo 666, N. 90. 
Cabe destacar que uno de estos reos que iba a bordo del "San Pedro de Alcántara" fue el hijo de Tupac Amaru, Fernando Condorcanqui. En marzo de 1784 la Audiencia de Lima le sentenció a diez años de trabajos forzados en un presidio español. En el navío "El Peruano" fueron embarcados Juan Bautista Tupac Amaru y Mariano Tupac Amaru. Otro personaje que se sumó a la tripulación fue el botánico francés Joseph Dombey, que de este modo se desvinculó de la expedición botánica de 1778 que también integraron Hipólito Ruiz y José Pavón.

En carta de 16 de julio de 1784, el comandante del "San Pedro de Alcántara", Manuel Fernández de Bedoya, informaba al virrey del Perú de las adversas circunstancias concurrentes en su primera navegación que le obligaron a recalar en el puerto chileno de la Concepción para proceder a las imprescindibles reparaciones. En dicha demarcación no se podía responder eficazmente a la rehabilitación del buque para tan larga carrera, al menos según consideraron los vocales de la junta reunida al efecto. Su regreso al puerto peruano significaba un retraso muy perjudicial para los intercambios comerciales, remisión de caudales y deterioro de los frutos americanos remitidos. A la consternación del comercio limeño por tal contratiempo, se unía la indignación oficial, pues recientemente se habían invertido sumas importantes en su puesta a punto. $\mathrm{Su}$ cargamento se depositó provisionalmente en Concepción, a cargo del maestre de plata Gaspar de Amenábar. Teodoro de Croix, receloso ante aquel episodio, recabó información y ordenó el arresto de Bedoya a bordo de su navío entretanto se aclarara lo sucedido gracias a los cargos formados por Antonio Vacaro ${ }^{23}$.

Fue el propio virrey del Perú quien informó a Gálvez de la llegada al puerto de la Concepción de Chile del navío "San Pedro de Alcántara", según le había transmitido previamente el maestre de campo de aquella guarnecida frontera en notificación canalizada por el barco del comercio de Lima "Santa Bárbara", llegado del puerto de Talcahuano que junto a Valdivia formaban el sistema defensivo en la región. La bahía de la Concepción, escenario del inoportuno paso de los reos del rey, era espaciosa y apta como fondeadero. Su principal puerto era el de Talcahuano, que «consiste en una ensenada que hace la costa [...] en él es donde dan fondo casi todos los navios y en donde pueden mantenerse con alguna seguridad porque el tendero es mejor que en todo lo restante de la bahía y hay algun abrigo para los nortes» ${ }^{24}$. Así pues, con capacidad, cualidades y resguardo suficientes ofrecía la mejor y urgente parada posible en las dilatadas costas australes del Mar del Sur.

23 Carta $n^{\circ} 82$ de Teodoro de Croix a José de Gálvez, 16 de septiembre de 1784, AGI, Lima, legajo 666, N. 89.

${ }^{24}$ Ulloa, 1990 [1748]: 278-279. 
Arribado a la bahía de Talcahuano el barco comandado por Bedoya, se amarró la embarcación bajo la protección del cañón del fuerte de Gálvez, levantado en la falda del cerro, en atención a aliviar su carga y, tras comprobar el estado del buque, advertir sobre la posibilidad o no de proceder a repararlo in situ, o bien en El Callao, donde a la sazón se encontraba el almacén principal de pertrechos navales. Igualmente, pasó oficio al comandante expresándole lo arriesgado que era desembarcar los reos que conducía «de los iniquos Tupac-amaros». Señalaba los graves perjuicios de tan delicada resolución, razones que parecieron muy fundadas al virrey de Lima y «dignas de que las oiga S. M.», pues así lo esperaba del secretario de Indias malacitano. El virrey encargó celosamente a Higgins y Bedoya que estuvieran «mui a la mira de la seguridad de estos reos y de pribarles toda comunicación con aquellos naturales ${ }^{25}$.

Además de la proyección del levantamiento andino en la frontera de Concepción, el episodio se nos antoja como un anticipo del futuro pánico de Floridablanca y su cordón sanitario ideológico para hacer frente a la regicida Convención francesa. El temor a las resonancias del tupamarismo en Perú y en otros dominios hispanoamericanos de la Monarquía Hispánica es un hecho probado historiográficamente ${ }^{26}$. La peor de todas las inquietudes por parte de la población criolla y mestiza peruana fue la imagen de unas poblaciones indígenas desenfrenadas buscando la inversión del orden social y la recuperación de su antiguo gobierno a través de una guerra racial ${ }^{27}$. También en la jurisdicción de Charcas se activó el miedo a un exterminio por parte de los indios sobre todo cuando el aymara Tupac Katari, aliado con líderes tupamaristas, expresó como objetivo de su revolución la conformación de un gobierno indio que requería el exterminio de los españoles blancos ${ }^{28}$. En el caso chileno, no se produjo este imponderable, pero las autoridades locales con motivo del paso de los dos navíos con los reos tupamaristas alentaron una precaución quizás exagerada sobre este asunto.

Vale la pena contemplar las razones alegadas por Higgins al comandante, en orden a que evidencian la política indígena implementada en la periferia imperial al amparo del reformismo de la mano de curtidos agentes del rey como Gálvez o Campomanes. A Higgins le sorprendió la osadía de Bedoya, transmitida oralmente por el teniente de navío Juan de Trujillo, en atención

25 Carta de Teodoro de Croix, virrey del Perú, a José de Gálvez, Secretario de Indias, 16 de julio de 1784, AGI, Lima, legajo 666, N. 56.

26 Stoetzer, 1989. Krebs y Gazmuri, 1990. Rosas Lauro, 2005 y 2006.

27 Szeminski, 1990. O'Phelan, 2005.

28 Thomson, 2006. 
al desembarco de los notables indios rebeldes, entre ellos diversos familiares de José Gabriel Tupac Amaru. El peligro inherente a tal medida preocupaba seriamente por tratarse de un territorio «cassi circundado de yndios ynfieles constantemente adictos á alborotos, y novedades mandados, por caziques atrevidos». Consecuentemente instaba a Bedoya a desistir de dicha arriesgada intención y, por el contrario, le pedía mantener embarcados a los insurrectos peruanos - indios y mestizos- - Su pragmatismo político y conocimiento del medio le exigían evitar todo contacto, con el beneplácito de la superioridad ${ }^{29}$.

La aciaga travesía del Pacífico sur del "San Pedro de Alcántara" tuvo, como hemos visto, una parada forzosa en la frontera chilena que por entonces estaba bajo el mando de Higgins. La repercusión de tan incómoda visita en el territorio fronterizo se tradujo en las enérgicas medidas tomadas al respecto para evitar en todo lo posible la comunicación entre los rebeldes andinos y los insumisos mapuche-araucanos. El oficio remitido por Higgins a Bedoya fue muy crítico. Resultaba escaso e insuficiente el traslado de la embarcación desde la punta de la Quiriquina al surgidero de Talcahuano y el resguardo de su pólvora en el fuerte vigilado por un piquete de la guarnición de la plaza, al mando de Juan Bautista de la Rueda. Ante la carencia de efectivos del navío, Higgins ordenó la marcha de dos destacamentos de infantería y dragones de refuerzo, pese al deficitario estado de los caminos máxime en invierno.

En lo relativo al desembarco de los reos y familiares del caudillo andino, la posible comunicación con los indígenas locales resultaba perniciosa «por mas cuidado que se tenga para embarazarlo», pues en la plaza abundaban mestizos e indios jornaleros. En efecto, señala Moreno Bazaes que «el temor a una posible comunicación entre los naturales, los mestizos y los Tupac Amaru era originado por un proceso gradual de ingobernabilidad producto del incremento del bandidaje, el despliegue de la insubordinación y la incipiente ola de violencia interpersonal» ${ }^{30}$. Aduce Moreno Bazaes que dicha inestabilidad se derivaba de un conflicto en la frontera entre el derecho monárquico y el derecho consuetudinario mapuche.

Higgins consideró que era aún peor el envío de los presos a los fuertes de la frontera. Tanto la presumible alteración provocada entre las naciones nativas inmediatas, como la posibilidad de que algún prisionero escapara bajo su protección, especialmente el joven hijo del cacique de Tinta, provocarían graves consecuencias para el inestable equilibrio fronterizo. Frente a ambos peligros de contagio o asilo, recomendaba que permanecieran en el navío o

29 Oficio de Ambrosio Higgins de Vallenar al virrey del Perú, Teodoro de Croix, 23 de junio de 1784, AGI, Lima, legajo 666, N. 56.

30 Moreno Bazaes, 2014: 44. 
bien transbordarlos a la fragata "Monserrate" por el tiempo que se prolongara la urgente reparación. En todo caso, resultaba ineludible evitar cualquier tipo de trato y diálogo entre los reos y los naturales del país, españoles incluidos $^{31}$. Atajar decididamente la génesis o propagación de todo conato de levantamiento y erradicar la difusión de ideas subversivas obedecía a la básica función de control de un fiel servidor del monarca. Los puestos de responsabilidad militar o de gobierno se debían ejercer desde la lealtad personal y política como doble vínculo.

Durante la primera estancia chilena del "San Pedro de Alcántara", Higgins había manifestado su total disconformidad respecto a que los familiares y copartícipes en el gran levantamiento transportados a España iniciaran cualquier tipo de contacto con los autóctonos del distrito bajo su mando. El miedo suscitado por el tránsito de los reos en la frontera era tan gratuito como irrefrenable en las mentes y directrices de las autoridades de la marginal región, pero se trata de un sentimiento que constituye «un componente mayor de la experiencia humana a pesar de los esfuerzos intentados por superarlo» ${ }^{32}$. Posiblemente operara más bien la angustia que el temor a una amenaza concreta, no obstante la superioridad demográfica indígena y larga data de su resistencia eran motivos más que suficientes para tomar precauciones extremas. Preservar la frágil seguridad, en el otro fiel de la balanza, hizo necesario tomar medidas materiales y simbólicas para la tranquilidad del territorio en respuesta a peligros más imaginarios que factibles. Entre la dicotomía planteada no cupo duda alguna: asegurar los mecanismos de control al máximo o incurrir en el mal riesgo de la inseguridad ${ }^{33}$. Sin embargo, la unidad de acción era irrealizable por la disparidad de reivindicaciones y evolución propia de cada grupo étnico, a su vez fragmentado o enfrentado en muchas ocasiones en aquel remoto país.

Resulta un misterio qué fue lo que provocó que durante la accidentada primera salida del "San Pedro de Alcántara" falleciesen nueve varones y siete mujeres, todos familiares de Tupac Amaru (cuadro 2). Las causas de estos decesos permanecen desconocidas, aunque la explicación más probable es que tal mortandad la provocasen el hacinamiento y la alta insalubridad ya que «El San Pedro de Alcántara llevaba el doble de su carga habitual, incluidas 600 toneladas de cobre, 153 toneladas de plata y 4 toneladas de oro» ${ }^{34}$.

31 Oficio de Ambrosio Higgins a Manuel Fernández de Bedoya, 20 de junio de 1784, AGI, Lima, legajo 666, N. 56.

32 Delumeau, 1989: 21.

33 Delumeau, 2002.

34 Walker, 2015: 264. 
Cuadro 2. Relación de familiares de Tupac Amaru fallecidos

en el "San Pedro de Alcántara” (DeSDe su Salida del PUERTo

DEl CAllaO, ARRIBADA a CONCEPCIÓN Y VUELTA

al Perú, Lima a 20 de Diciembre de 1784)

\begin{tabular}{|l|l|}
\hline \multicolumn{1}{|c|}{ Hombres (9) } & \multicolumn{1}{c|}{ Mujeres (7) } \\
\hline Juan Tomás Palomino & Ascencia Fuentes Castro \\
Ignacio Quispe & Santusa Castro \\
Melchor Ramos & Margarita Noguera \\
Crispín Guaman & Lorenza Mendigure \\
Antonio Camaqué & Bartola Escovedo \\
Marcelo Luque & Nicolasa Aguirre \\
Antonio Castro & Antonia Castro \\
Francisco de Castro & \\
Juan Barrientos & \\
\hline
\end{tabular}

Fuente: AGI, Lima, legajo 666, N. 90.

De vuelta al puerto peruano, se rehizo la lista de reos dejando constancia de los muertos durante el tornaviaje como vimos más arriba y, por fin, se elaboró una nómina definitiva para la segunda travesía, cuyo cómputo ascendía a veinticinco: dieciséis indios, uno de ellos tan solo un niño, - contando a un nuevo partidario tupacamarista capturado por el intendente de Huamanga - y un francés junto a ocho nativas, pues una desahuciada quedó en el hospital de Bellavista próximo al Callao (cuadro 3). El destierro del Perú y el aislamiento en Chile fueron las mejores estrategias, entendían en Lima, para «evitar las consequencias que podrían dimanar» de su permanencia o contacto con aquellos «ilusos Naturales» ${ }^{35}$.

El virrey del Perú Croix informó a Gálvez que en el referido navío "San Pedro de Alcántara", que partió de Lima el 20 de diciembre de 1784 al mando del comandante Manuel de Eguía, junto con los prisioneros tupamaristas remitía bajo partida de registro al religioso agustino fray Juan de Alcedo, autor de una sátira contra el gobierno que él mismo dejó en el gabinete virreinal, donde se presentó bajo nombre falso. Los autos originales de la causa, remitidos y embarcados junto al reo, se perdieron con su naufragio. No obstante, valga citar la opinión del virrey sobre el texto al secretario de Indias:

35 Carta $n^{\circ} 122$ de Teodoro de Croix a José de Gálvez, 20 de diciembre de 1784, AGI, Lima, legajo 666, N. 90. Adjuntas corren las tres Relaciones de individuos mencionadas: la correspondiente a la primera salida, la que deja constancia de los fallecidos y la definitiva o de la segunda salida con destino a Cádiz. 


\section{Cuadro 3. Relación de familiares de Tupac Amaru que en partida DE REgistro CONDUCE EL "SAN PEDRo DE AlCÁNTARA" (SEGunda SAlidA A CÁdiz, Lima A 20 DE DiCiembre de 1784)}

\begin{tabular}{|l|l|}
\hline \multicolumn{1}{|c|}{ Hombres (17) } & \multicolumn{1}{c|}{ Mujeres (8) } \\
\hline Fernando Condorcanqui & Francisca de Fuentes Castro \\
Andrés Mendigure & Paula Castro \\
Manuel Silvestre Rojas & Paula Noguera \\
Nicolás Almendras & Patricia Díaz \\
Pablo Quispe & María Luque \\
Blas Guaman & Felipa Mendigure \\
Silvestre Luque & Antonia Caya \\
Lorenzo Noguera & Santusa Canqui \\
Ambrosio Mendigure & \\
Mariano Mendigure & Manuela Tito Condori, viuda de Diego \\
Pedro Venero & Cristóbal Tupac Amaru - primo y sucesor \\
Antolin Ortiz & del caudillo andino-, no embarcó por \\
Francisco Castro & enfermedad grave y permaneció en el \\
José de Castro & hospital de Bellavista. \\
Pedro Antonio (niño) & \\
Diego Xaquica (procedente de Huamanga) & \\
Antonio Alejandro Bergni (francés) & \\
[sic Berney] & \\
\hline
\end{tabular}

Fuente: AGI, Lima, legajo 666, N. 90.

«la mas denigrativa é injuriosa á los Ministros del Rey que pudiera imbentar la malicia» ${ }^{36}$.

El segundo arribo del "San Pedro de Alcántara" a la bahía de Talcahuano se produjo el 22 de enero de 1785 . Entre la población local se produjo una extrema inquietud social ante esta segunda presencia del navío. Esta no tanto por la presencia de los prisioneros tupamaristas sino debido a que entre la tripulación se declaró un brote de viruela. El comandante general de la frontera Higgins tuvo que asumir la conducción de las medidas sanitarias que condujeron a aislar al navío español de la población para evitar así el contagio de la peste ${ }^{37}$. La junta presidida por Higgins determinó que el navío se trasladase a Valparaíso donde existían establecimientos hospitalarios especializados en el tratamiento de la enfermedad, solución que rechazó el comandante Eguía. Para la tranquilidad popular el navío se trasladó a la cercana isla de la Quiriquina, donde los enfermos

36 Carta $n^{\circ} 124$ de Teodoro de Croix a José de Gálvez, 19 de diciembre de 1784, AGI, Lima, legajo 666, N. 91.

37 Moreno Bazaes, 2014. 
fueron aislados. Una vez curada la tripulación el "San Pedro de Alcántara" retornó al puerto de Talcahuano y desde allí tomó rumbo a Río de Janeiro.

El navío de guerra "San Pedro de Alcántara" prosiguió su navegación con otras escalas y naufragó frente a las costas meridionales lusas. Previamente, el 5 de diciembre de 1785, había recorrido la isla de la Ascensión y el 23 de enero la de Santa María (archipiélago de las Azores). De allí, con tiempo adverso, se dirigieron rumbo a España, avistando tierra el 2 de febrero. A las diez y media, bajo un chubasco, no pudieron impedir su choque contra una altiva peña. El dramático hundimiento aconteció la noche del 2 al 3 de febrero de 1786, en los alrededores de la villa de Peniche en el litoral portugués, a la altura de las islas Berlingas, precipitándose contra la roca de Papona, situada a cierta distancia del fuerte Nuestra Señora de la Luz. Había emprendido la singladura en Lima el 14 de abril de 1784, arribó tras agitado viaje a la chilena y austral Concepción, pero regresó el 14 de septiembre para la Ciudad de los Reyes. Por segunda vez salió de El Callao el día 21 de diciembre para arribar de nuevo a Chile el 22 de enero de 1785 y de allí navegó hasta Río de Janeiro, donde echó las anclas a principios de junio. Dio vela para Cádiz el 4 de noviembre y se perdió a principios del año siguiente frente a la costa lusa como fatal colofón de su derrotero. El embajador de España en Lisboa, conde de Fernán Núñez, señaló tanto a Madrid como al comercio de Cádiz que actuaran debidamente con la finalidad de eludir molestas especulaciones sobre la noticia que mermaran el prestigio de la nación. Por su parte, el vicecónsul Francisco Antonio Denis Carvallo y su familia socorrieron de modo ejemplar a los tripulantes junto a las autoridades locales. Incluso se arriesgó personalmente bajo el buque hundido en las labores de auxilio y rescate.

Además de los considerables caudales de metales preciosos —oro y plata-, y los equipajes de oficiales y pasajeros, se perdieron en el naufragio valiosos frutos naturales remitidos desde el virreinato del Perú, quintales de cobre, cajones de cascarilla, cacao y cañas de Guayaquil, macetas de plantas vivas — plantones de araucaria y piñas remitidas por Higgins a Gálvez-, bálsamos, resina, muestras de madera y lana o plantas de uso medicinal como canchalagua y calaguala e incluso cajones rotulados a nombre de José de Gálvez. Respecto a la pérdida de vidas humanas, ascendió a 128 entre plana mayor del navío, oficiales de transporte y pasajeros. Heridos resultaron 58 y sanos 233. A bordo eran transportados camino del destierro 24 indios presos, 17 hombres y 7 mujeres, de dicha cantidad 18 perecieron, la familia de Juan Bautista Tupac Amaru incluida ${ }^{38}$.

38 La cifra varía poco si cotejamos documentación y prensa: Mercurio de España, (Madrid, febrero 1786): 206-216. Para la carga del buque: Carta de Vacaro a Valdés desde Lima, 13 de abril de 1784, Archivo General de Marina “Álvaro de Bazán”, Expediciones a Indias, 
Aparte de las fuentes, autores señalan que el total de fallecidos fue de 152, computando 5 mujeres, 14 oficiales —uno de ellos, el teniente coronel de infantería Nicolás Maguara, junto a su esposa y cuatro hijos-y 128 individuos de marinería y tropa, sin tener en cuenta los que murieron con posterioridad como resultado de las heridas sufridas. El principal causante de dicha mortandad fue, según testimonio del comandante, el desesperado intento de muchos por ganar la playa a nado, así como la rápida descomposición del navío. Conocido el siniestro, el embajador español recibió órdenes de auxiliar a los náufragos de la playa y se solicitó el socorro a Cádiz, El Ferrol y Vigo, puertos que enviaron buques disponibles con jarcia, aparejos y raciones ${ }^{39}$.

Junto al alférez de dragones Luis de Benavente, sobrino del duque de San Carlos, se ahogó el teniente de infantería Hugo O'Falvey, de neta estirpe irlandesa, uno de los varios jefes y oficiales que fenecieron en el letal naufragio. Asimismo, entre los presos bajo partida de registro se encontraba el agustino fray Juan Alcedo, como vimos autor de unos versos satíricos sobre la administración hispana, desterrado por orden del virrey Teodoro de Croix ${ }^{40}$. Todos los exiliados forman una panoplia variopinta que rescatamos al modo clásico: «Ahora, yo quisiera narrar el linaje y el nombre/ de los héroes, del largo mar los caminos, y cuantos hechos cumplieron/ mientras iban vagando $»^{41}$. Además, llenamos así un vacío historiográfico sucintamente apuntado ${ }^{42}$.

\section{Los Tupac Amaru más allá del marco Cronológico y eSPACial PERUANO}

De la presencia más allá del Atlántico de personas emparentadas con el famoso cacique o curaca, conocemos sus trayectorias que fueron de lo más sorprendentes. En algún caso, el regreso en el contexto de las emancipaciones americanas resultó clarificador por el testimonio legado. Tal fue el caso de Juan Bautista Tupac Amaru, que una vez liberado del presidio de Ceuta retornó a Hispanoamérica y redactó unas memorias por encargo del gobierno argentino. El suyo fue un caso paradigmático en este sentido, pues a su triste

legajo 2, doc. 6, n. ${ }^{\circ} 16$ y Estados de Fuerza y Vida, 2235-41 (El Callao, 28 de diciembre de 1784). Véase Melgar Bao, 2010.

39 Fernández Duro, 2009 [1867]: 88-103.

40 Palma, 1961: 725-731 ("La gatita de Mari-Ramos, que halaga con la cola y araña con las manos. Crónica de la época del trigésimo cuarto virrey del Perú, 1788”).

41 Rodas, 1991: 54 [I, 20-22].

42 Vaca de Osma, 2005: 277. 
recorrido y vicisitudes de dilatado cautiverio se unió su fidelidad a la causa social abanderada por su medio hermano cuzqueño.

Los tupamaristas que arribaron a territorio peninsular en 1785 sufrieron penalidades en mayor o menor grado. A continuación, se analizará la prolongación de los padecimientos de los parientes de José Gabriel Condorcanqui en la Península Ibérica. No es nuestro propósito estudiar aquí al conjunto de reos — que merecería un análisis prosopográfico independiente— ${ }^{43}$, su trágico traslado terrestre del Cuzco a Lima durante cincuenta y tres días y estancia en el Real Felipe una vez custodiados en el presidio del Callao según el virrey Teodoro de Croix ${ }^{44}$, o su posterior itinerario marítimo bioceánico, sino acometer la estancia forzada en Talcahuano del "San Pedro de Alcántara", como vimos. Pero resulta muy ilustrativo recuperar algunas incidencias del viaje y la llegada a Cádiz y después Ceuta para comprender la proyección futura de los Tupac Amaru en suelo africano y europeo, componiendo así un retazo de historia americana tricontinental.

Juan Bautista Tupac Amaru en sus memorias tituladas Cuarenta años de cautiverio recoge toda la aspereza del traslado de la tripulación en "El Peruano". Este pudo arribar al emporio gaditano y concluir el destierro de aquellos infortunados treinta y ocho niños/as, hombres, mujeres y ancianos/as que acompañaban a Juan Bautista. Según informaba el visitador general Jorge Escobedo al ministro Gálvez, habían zarpado del Callao el 13 de abril de 1784, y tras algo más de diez meses de penalidades en tan larga travesía echó el ancla en febrero de 1785. Por el camino, y siguiendo la ruta del Estrecho de Magallanes, tuvieron que hacer escala desde junio hasta noviembre en Río de Janeiro por contar dicho puerto con recursos suficientes para las costosas reparaciones que se presentaron, prácticamente a los cuatro meses de su partida de Lima, donde se computaron como era habitual los fallecidos en dicho derrotero (cuadro 4). Igualmente, para arreglo del timón de la embarcación se hizo necesaria otra parada en Montevideo.

En este accidentado trayecto perecieron dieciséis reos por enfermedad natural, como informó su comandante el jefe de escuadra José de Córdova y Ramos al secretario de Indias. Le acompañaban como parte de la tripulación el maestre de plata Martín José de Echenique y el contador José de Vargas Machuca. Cabe imaginarse los estragos físicos y morales que supuso la ex-

43 Lista de reos en: Carta del virrey Teodoro de Croix al ministro de Indias José Gálvez, 20 de diciembre de 1784, AGI, Lima, legajo 666, N. 90. Para una visión general: Correspondencia y expedientes sobre sublevaciones en el Perú (José Gabriel Tupac Amaru, 1780-1782), AGI, Lima, legajo 1039.

44 Fuentes, 1859: 207. 
Cuadro 4. Relación de indígenas fallecidos del navío "El Peruano" EN LA NAVEGACIÓN DESDE LIMA A Río DE JANEIRO, A BORDO DEL EXPRESADO NAVÍO, AL ANCLA EN EL PUERTO CITADO A 10 DE AGOSTO DE 1784

\begin{tabular}{|c|c|c|}
\hline Hombres (8) & Mujeres de los anteriores (4) & $\begin{array}{c}\text { Hijos/as de } \\
\text { menor edad (4) }\end{array}$ \\
\hline 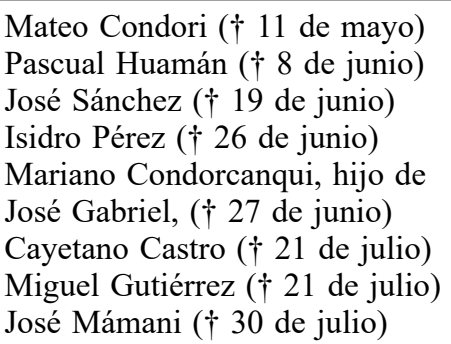 & $\begin{array}{l}\text { Susana Aguirre } \\
(\dagger 20 \text { de abril) } \\
\text { Antonia de Castro († } \$ \text { de mayo) } \\
\text { Nicolasa Torres } \\
(† 1 \text { de junio) } \\
\text { Andrea Cózcamayta o Cúscamayta } \\
(† 3 \text { de agosto) }\end{array}$ & $\begin{array}{l}\text { Gregorio Tito } \\
(\dagger 27 \text { de mayo }) \\
\text { Feliciana Tito } \\
\left(\dagger 1^{\circ} \text { de junio }\right) \\
\text { María Tito } \\
(\dagger 10 \text { de julio }) \\
\text { Juliana Tito } \\
(† 5 \text { de agosto })\end{array}$ \\
\hline
\end{tabular}

Fuente: Loayza, 1941: 142.

tirpación de su tierra andina y la dureza de la vida a bordo de barcos de guerra de los familiares y partícipes de la colosal revuelta encabezada por Tupac Amaru en calidad de presos por rebeldía.

Una vez que llegaron a Cádiz, por reales órdenes, Juan Bautista y sus sobrinos Mariano y Fernando Condorcanqui, así como Andrés Mendigure Tupac Amaru debían ser apartados en una prisión más segura que el resto. La alta custodia cesaría cuando fueran trasladados a destino definitivo. El conde Alejandro O'Reilly, a la sazón capitán general de Andalucía comisionado para reorganizar el sistema defensivo de la bahía gaditana, acusaba recibo al ministro de Indias el 12 de octubre de 1784. No obstante, Mariano falleció a la edad de 21 años durante la travesía.

Por oficio de 25 de febrero de 1785 a José de Gálvez del presidente de la Casa de Contratación de Cádiz, Bartolomé de Ortega, conocemos la relación de los veintiún pasajeros - españoles americanos y peninsulares, lusos, flamencos e incluso el botánico galo José Dombey - y veintinueve presos que transportaba "El Peruano" aparte tripulación, cuya lista es la que sigue: Felipe González Tímaycocayme, Mariano Barrera, Pedro Nolasco Simbrón ${ }^{45}$, Antonio Gramurete [sic Gramusset], Nicolás Victorino, Francisco Ruano, Blas Laso, Manuel Tito y Juan [Bautista] Tupac Amaru; además de los niños Mariano y Miguel Tito. A los muertos habidos en la travesía entre El Callao y Río de Janeiro, vinieron a sumarse los dos fallecidos en el puerto brasileño,

45 Cacique o curaca de Checras que encabezó una revuelta en 1781. AGI, Lima, legajo 1048. Citado por O'Phelan Godoy, 1988: 307. 
a saber, Bartolomé Guamán y Gregorio Mallqui. Finalmente, arribaron vivos a Cádiz nueve adultos y dos niños, quienes fueron entregados por el oficial de guardia del navío en cuestión, Diego Machado, al alguacil de la Real Audiencia Cayetano Monleón. Habían fallecido desde la partida de América dieciocho. Bajo la custodia de la preceptiva tropa proporcionada por el gobernador, bajaron a tierra y fueron trasladados por el comisionado sargento mayor Francisco Codony separadamente: seis al castillo de Santa Catalina y cinco al de San Sebastián, extramuros de la plaza ${ }^{46}$, según informaba en relación adjunta al oficio de la misma fecha Calixto Vani. El virrey Jáuregui aconsejó su destierro en la Península y no en África para bloquear cualquier intento de rescate por una potencia enemiga.

Una segunda relación, de Codony, especificaba los destinos de ambos grupos con arreglo a las Reales Órdenes de 24 de marzo y 30 de julio de 1784. En el castillo de San Sebastián quedaban Felipe González Timaycocaimi, Mariano Barrera, Pedro Nolasco Simbrón, Nicolás Victoriano y Juan Bautista Tupac Amaru. Por su parte, al de Santa Catalina fueron a parar Antonio Gramusset, Francisco Ruano, Blas Laso, Manuel Tito, Mariano y Miguel Tito, de doce años de edad. Allí permanecieron más de tres años, de los once siete perecieron en sus calabozos, mientras que cuatro sobrevivieron a la fortificación: Juan Bautista, Pedro Nolasco, Nicolás Victoriano y Francisco Ruano.

También se informó junto al depósito de los mismos en los castillos de la ciudad, de las cantidades proveídas a cuenta de la Real Hacienda para su manutención, así como que «nada se escasee» para la curación de Antonio Gramusset, en estado grave, Francisco Ruano y el niño Mariano Tito. El primero era francés y compañero de Antonio Vergne [sic Berney], ambos encausados remitidos por separado a disposición del Consejo de Indias por su participación en la conocida como "Conspiración de los tres Antonios" junto a Antonio de Rojas para independizar Chile. No disponía de los autos, pero presumía que vendrían junto a Berney en el "San Pedro de Alcántara", que se hundió como sabemos, hecho que produjo que pereciera junto al joven Andrés Mendigure ${ }^{47}$. Respecto a los supervivientes de su naufragio, fueron encerrados en los mismos castillos gaditanos. Por último, en 1788 - año de la muerte de Carlos III, cerrando un capítulo al comienzo de un nuevo reinado - se sacó a todos los andinos procedentes de ambos navíos y se les distribuyó por España con una acusada dispersión geográfica, sin olvidar su correspondiente asignación a cargo del rey, lo cual no evitó miserias o priva-

\footnotetext{
46 Solís, 1969: 169-170.

47 Olivia de Coll, 1991: 237.
} 
ciones personales. La lista de supervivientes de los aproximadamente sesenta y nueve es la que sigue (cuadro 5) ${ }^{48}$.

Cuadro 5. Nota de las personas que han venido del Perú y Provincias de Buenos Ayres, a disposición de este Ministerio de INDIAS, DE RESULTAS DE LAS ÚLTIMAS REVOLUCIONES DE AQUELLOS REYNOS, Y SE HAN DESTINADO A RESIDIR EN ESTOS DE ESPAÑA, POR EL TIEMPO DE LA VOLUNTAD DE S. M., EN LOS PUEBLOS Y CIUDADES QUE SE EXPRESAN, Y CON LAS ASIGNACIONES QUE POR VÍA DE ALIMENTOS VAN TAMBIÉN SEÑALADAS. CÁDIZ, 26 DE ABRIL DE 1788

\begin{tabular}{|l|c|c|}
\hline Nombre & $\begin{array}{c}\text { Localidad de } \\
\text { residencia }\end{array}$ & $\begin{array}{c}\text { Cantidad diaria para } \\
\text { alimentos en reales }\end{array}$ \\
\hline Sebastián López Armijo & Valladolid & 8 \\
Miguel Bastidas con su mujer y un hijo & Zaragoza & 16 \\
Pedro Nolasco Simbrón & Burgos & 6 \\
Fernando Tupac Amaru & Getafe & Escuela Pía \\
Nicolás Victorino & Daroca & 6 \\
Juan Bautista Tupac Amaru & Ceuta & 6 \\
Francisco Ruano & Ciudad Rodrigo & 6 \\
Francisco de Castro & Zamora & 6 \\
José de Castro & Lérida & 6 \\
Paula de Castro & Madrid & Colegio de Monterrey \\
María Luque & Madrid & Colegio de Monterrey \\
\hline
\end{tabular}

Fuente: Loayza, 1941: 149.

Dos casos - tío y sobrino por línea paterna-, posiblemente los más significativos del destierro a perpetuidad, nos sirven para concluir nuestro trabajo: Juan Bautista Tupac Amaru y Fernando Tupac Amaru. El primero permaneció tres años y tres meses en el castillo de San Sebastián hasta que el rey ordenó la dispersión de los reos supervivientes por el interior del reino y en los presidios norteafricanos. Pasó por la Isla de León y Sancti Petri, desde donde fue conducido a Ceuta sobre la carga de sal del buque llegando el primero de junio de 1788. Antes de su vuelta en loor de multitudes al continente americano, en concreto al Buenos Aires de la efervescencia republicana donde recibió una pensión del gobierno y redactó su historia ${ }^{49}$, estuvo en el

48 Loayza, 1941: 140-149. Otros autores elevan a noventa la cifra total de deportados a España: Caranci, 1987: 126.

49 Astesano, 1979: 126. 
presidio ceutí y dejó rastro como avecindado en el callejón de San Simón según consta en el padrón de $1818^{50}$. Liberado por un indulto del gobierno liberal español, la fecha más probable de su embarque y llegada a Buenos Aires fue en la segunda mitad de 1822. Además, un impreso nos indica su llegada ese mismo año, octogenario tras casi cuarenta de cautiverio ${ }^{51}$. Es más, el propio protagonista nos informa definitivamente sobre la versión y en primera persona del proceso liberatorio y la vuelta a América en iguales términos cronológicos.

Los sucesos de la agónica metrópoli repercutieron en la trayectoria individual de Juan Bautista. Hasta 1820 albergaba esperanzas continuas y crecientes en el retorno y estaba al tanto, en la medida de lo posible, de los pormenores de las guerras civiles americanas. Dicho año las Cortes, coincidiendo con la revolución iniciada por Riego y el Trienio Liberal, decretaron la puesta en libertad de los americanos presos por opiniones políticas y la entrega de diez reales de vellón diarios hasta el embarque, igualmente sufragado, con destino a sus provincias. Desafortunadamente un accidente retuvo su ímpetu y el ya anciano tuvo que posponer la marcha a Algeciras, donde recibió mejor trato de varias personas, entre ellas el general americano de origen irlandés Demetrio O'Daly ${ }^{52}$. Sostuvo la posibilidad de pasar a Gibraltar y de allí a Indias, pero quedó frustrada. Y siempre tuvo que enfrentarse con la penuria económica, que mermaba su esperanza de navegación atlántica. Finalmente, embarcó el 3 de julio de 1822 y puso rumbo a la América meridional el 3 de agosto. Durante la travesía hasta Buenos Aires sus achaques no desaparecieron y contó con la incesante ayuda de su amigo, que lo era desde 1813, el sacerdote Marcos Durán Martel ${ }^{53}$. En la capital argentina ambos fueron recibidos por Mariano Suvieta. En 1825, Juan Bautista remitió desde Buenos Aires una carta a Simón Bolívar reconociéndolo como Libertador de América en unos términos que lo legitimaban concatenando su obra con la del caudillo indio de los Andes: «A ella propendió Don José Gabriel Tupamaru, mi tierno y venerado hermano, mártir del Imperio peruano, cuya sangre fue el riego que

50 Padrón de 1818, legajo 1, libro 2, fol. 33, Archivo Parroquial de Nuestra Señora de los Remedios de Ceuta. Véase sobre la vida en la plaza: Martín Ruiz, Pazzis Pi Corrales y Gimena, 2016.

51 Tamayo Herrera, 1816 [1981]: VI.

52 Militar puertorriqueño que participó en la Guerra de la Independencia española, fue representante en las Cortes de Cádiz y apoyó el levantamiento liberal. Factores que sirven para explicar su actitud benévola hacia el peruano. Véase al respecto: Fernández Pascua, 2013.

53 Durán Martel estuvo implicado en los hechos que se conocen como la rebelión de Huánuco de 1812. 
había preparada aquella tierra para fructificar los mejores frutos que el Gran Bolívar había de recoger» ${ }^{54}$.

Como epílogo, un par de episodios son relevantes de la situación de Juan Bautista durante las décadas ceutíes. En una ocasión que salió de paseo a contemplar unos ejercicios militares, confundido entre la multitud, recibió ante el asombro generalizado un bastonazo en la cabeza por parte del comandante de la tropa. Cuando se recuperó, atribuyó a sus marcadas facciones indígenas americanas la agresión. Poco después, tuvo conocimiento de la muerte repentina de aquel oficial al que achacaba una animadversión común. El segundo suceso fue mucho más tormentoso por su causante. Casualmente por la calle un indio le preguntó si era cuzqueño, a lo cual contestó que era Tupac Amaru. El paisano, «lleno de furia me dijo cómo me tenían todavía con vida, que había mucho debían haberme muerto» ${ }^{55}$.

Respecto a Fernando Tupac Amaru, que era un niño de diez años cuando tuvo que presenciar en la plaza del Cuzco la ejecución de sus padres - José Gabriel Tupac Amaru y Micaela Bastidas - y la de su hermano Hipólito, su vida fue un triste peregrinar indiano y allende el océano. Aislado en la antigua capital y conducido hasta Lima para ser encerrado en el presidio del Callao entretanto fuera enviado a España, según testimoniaba el virrey en 1782 tras recibir las pertinentes órdenes. Fue uno de los supervivientes del naufragio del "San Pedro de Alcántara" y pasó como el resto de la familia directa y extensa del cacique de Tungasuca por Cádiz. Preso en el castillo de Santa Catalina escribió un memorial el 7 de septiembre de 1787, cuando contaba apenas con dieciséis años de edad. Como resultado, una nota de la Secretaría de Indias de 1788 informaba que había sido destinado a las Escuelas Pías de Getafe ${ }^{56}$. El 1798, poco antes de su muerte y estando como residente en Madrid, pidió licencia para pasar a tomar los baños de Sacedón (balneario a orillas del río Guadiela en Guadalajara) por orden facultativa al ser indispensable para los males que padecía por entonces, así como una ayuda de costa para sufragar los gastos en consideración a las grandes privaciones que padecía ${ }^{57}$.

54 Carta de Juan Bautista Tupac Amaru al Libertador Simón Bolívar, 15 de mayo de 1825. En Valcárcel, 1972: 908-909.

55 Loayza, 1941: 46-65.

56 Expediente sobre la remisión a estos Reinos [de España] de Fernando Tupac Amaru, hijo del rebelde José Gabriel y destino que se le ha dado en el Colegio al cargo de los Padres Escolapios de Getafe, 1782-1788, AGI, Lima, legajo 1049.

57 Memorial de Fernando Tupac Amaru, 15 de julio de 1798, AGI, Charcas, legajo 598. Expediente del destino de las personas que vinieron a España como consecuencia de la sublevación de Tupac Amaru (para Fernando los documentos abarcan de 1784 a 1798). 
Las penurias le rodearon en su formación y la salud resentida no le abandonó, tuvo un triste destino como toda aquella comitiva de desterrados. Murió el último de los incas con el ocaso del siglo, en los albores del siguiente su tío retornó al Nuevo Mundo. Su tío materno Miguel Bastidas, esposa e hija fueron enviados a Zaragoza. La eventual proyección más allá de los Pirineos de los tupamaristas se nos presenta como un tema sugestivo, pero con las necesarias cautelas ${ }^{58}$. Como siempre las líneas de investigación permanecen abiertas a la reconstrucción social de la historia.

La opinión de las autoridades españolas radicadas en el territorio fue que se hizo justicia, imponiendo con el celo debido «las justas penas, después de haberse seguido un prolijo, circunstanciado y extenso proceso ${ }^{59}$. En aquel momento, el levantamiento fue percibido en todo su peligro. Humboldt así lo matizaba en el contexto de un mundo atlántico en ebullición: «El grande alboroto de 1781 estuvo á pique de quitar al rey de España toda la parte de las montañas del Perú, en la misma época en que la Gran Bretaña perdía casi todas sus colonias en el continente de América» ${ }^{60}$.

Pero la perspectiva histórica no debe confundirse con la ucronía, mientras que la literatura se puede permitir unas licencias que la investigación científica rechaza. En este sentido, varios textos recuperan la memoria de los exiliados, en especial de los dos objeto de aproximación, así como de José Gabriel Tupac Amaru ${ }^{61}$. Desde la divulgación, a diferentes niveles y con recientes aportes, también se contribuye meritoriamente a esta justa puesta en valor $^{62}$. De igual manera que el rescate historiográfico debe contemplar el papel jugado por las mujeres. En este sentido, son dignas de mención tanto obras pioneras como actualizaciones en el marco de una visión renovada ${ }^{63}$. La presencia literaria e iconográfica de lo tupamarista es abundante y se proyecta culturalmente desde la génesis republicana hasta el presente, pero $a$ posteriori - baste recordar a Velasco Alvarado— ${ }^{64}$, siendo escasa la coetánea por razones obvias ${ }^{65}$. No obstante, sobre la descripción de Tupac Amaru tenemos varios testimonios que nos ofrecen una imagen más que interesante y un reto para la investigación ${ }^{66}$. La temática, si bien de longeva tradición in-

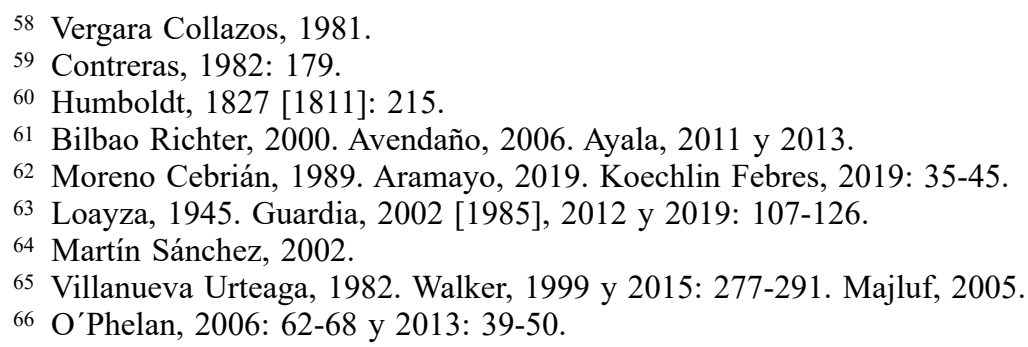


vestigadora, presenta múltiples aristas merced a su complejidad y riqueza. En consecuencia, se encuentra en construcción y siempre abierta a un fructífero debate.

\section{CONCLUSIONES}

Nuestra propuesta de análisis era doble. Por un lado, la trascendencia del paso de los reos de lesa majestad por el Chile meridional, por otro lado, la relevancia de aquellos pocos que sobrevivieron a la larga y penosa travesía hasta llegar a España y ser confinados en sus presidios norteafricanos. Si nos atenemos al conjunto de la producción más reciente, nuestra línea de investigación aporta una visión novedosa y parcialmente inédita acerca del trasiego de los prisioneros tupamaristas desde una perspectiva transatlántica.

Los avatares de la travesía, el paso por Chile de los navíos de registro con los prisioneros tupamaristas y la suerte de los exiliados proporcionan un epílogo digno de ser rescatado, así como también el temor ante el reavivamiento de las cenizas de la insurrección y su amenazante perpetuación en la memoria del imaginario de los Andes. El recorrido de su representación como signo de alarma posterior en el altiplano peruano o la frontera araucana, las prevenciones ante la perpetuación de la amenaza que encarnaban familiares, colaboradores y amigos desde la mirada de la autoridad dominante, y el largo periplo colectivo y personal de los desterrados configuran nuestro estudio. En definitiva, una microhistoria cruzada de dolor, miedo y esperanza. Al fin y al cabo, el papel de las emociones en la historia es importante para su comprensión y admite un enfoque interdisciplinario con la antropología, por ejemplo. Los derrotados por la historia no deben ser los olvidados por los historiadores.

Finalmente, el prolongado encarcelamiento en España de dos personajes como Juan Bautista Tupac Amaru y Fernando Tupac Amaru nos permite afirmar que, a pesar de su confinamiento, ambos personajes se abstuvieron de promover los objetivos políticos del líder cuzqueño. Fernando falleció mientras cumplía su condena en tanto que Juan Bautista fue el único pariente de José Gabriel Condorcanqui que retornó a Hispanoamérica. Tras ser indultado durante el Trienio Liberal, Juan Bautista expresó su intención de vindicar la actuación de su medio hermano. Tanto en sus memorias como en sus cartas a Bolívar, donde recordaba a este último el protagonismo precursor de su pariente cuzqueño, no pretendieron otro propósito que rescatar del olvido la rebelión de Tupac Amaru II. 


\section{BIBLIOGRAFÍA}

Aramayo, Omar, Los Túpac Amaru 1572-1827, Lima, Sinco Editores, 2019.

Astesano, Eduardo, Juan Bautista de América. El rey inca de Belgrano, Buenos Aires, Castañeda, 1979.

Avendaño, Ángel, Túpaq Amaru. Los días del tiempo profético, Lima, Instituto Nacional de Cultura-UNMSM, 2006.

Ayala, José Luis, Este cautiverio y agonía sin fin. Fernando Tupac Amaru Bastidas, Lima, AFA, 2011.

Ayala, José Luis, Juan Bautista Tupac Amaru. El dilatado cautiverio, bajo el gobierno español, de Juan Bautista Tupac Amaru, $5^{\circ}$ nieto del último emperador del Perú, Lima, Fondo Editorial Cultura Peruana, 2013.

Bilbao Richter, José, Juan Bautista Tupac Amaru y el misterio de la Orden del Sol, Buenos Aires, 1884 Editores-Editorial Círculo Militar, 2000.

Bonilla, Heraclio, Metáfora y realidad de la Independencia del Perú, Lima, IEP, 2001.

Busto Duthurburu, José Antonio del, Túpac Yupanqui, descubridor de Oceanía, Lima, Editorial Brasa, 2000.

Cajías de la Vega, Fernando, "Repercusiones de la revolución tupacamarista en la villa de Oruro y comarcas aledañas", Actas del Coloquio Internacional: "Tupac Amaru y su tiempo", Lima, Comisión Nacional del Bicentenario de la Rebelión Emancipadora de Tupac Amaru, 1982: 113-134.

Cajías de la Vega, Fernando, Oruro 1781: sublevación de indios y rebelión criolla, La Paz, Instituto de Estudios Bolivianos-IFEA, 2004.

Caranci, Carlo A., Tupac Amaru, Madrid, Historia 16-Ediciones Quorum-Sociedad Estatal para la Ejecución de Programas Quinto Centenario, 1987.

Chauca García, Jorge, José de Gálvez, mentor del irlandés Ambrosio Higgins en España y América, Málaga, Universidad de Málaga, 2016.

Contreras, Remedios (ed.), Relación y documentos del gobierno del virrey del Perú, Agustín de Jáuregui y Aldecoa (1780-1784), Madrid, CSIC, 1982.

Cornejo Bouroncle, Jorge, Tupac Amaru, la revolución precursora de la emancipación continental, Cusco, Universidad Nacional San Antonio Abad del Cusco, 2013 [1949].

Delumeau, Jean, El miedo en Occidente (Siglos XIV-XVIII). Una ciudad sitiada, Madrid, Taurus, 1989.

Delumeau, Jean, "Seguridad. Historia de una palabra y de un concepto", Marta Inés Villa Martínez (ed.), El miedo, Reflexiones sobre su dimensión social y cultural, Medellín, Corporación Región, 2002: 71-82. 
Durand Flores, Luis, Independencia e integración en el plan político de Tupac Amaru, Lima, PLV, 1973.

Eguiguren, Luis Antonio (ed.), Guerra separatista. Rebeliones de Indios en Sur América. La sublevación de Tupac Amaru. Crónica de Melchor de Paz, t. II, Lima, Imprenta Torres Aguirre, 1952.

Faverón Patriau, Gustavo, Rebeldes. Sublevaciones indigenas y naciones emergentes en Hispanoamérica en el siglo XVIII, Madrid, Tecnos, 2006.

Fernández Duro, Cesáreo, Naufragios de la armada española. Relación histórica formada con presencia de los documentos oficiales que existen en el archivo del Ministerio de Marina, Sevilla, Editorial Renacimiento, 2009 [1867].

Fernández Pascua, Delfina, "Ramón Power y Demetrio O'Daly: diputados a Cortes por Puerto Rico", Enrique García Hernán y M. a del Carmen Lario de Oñate (eds.), La presencia irlandesa durante las Cortes de Cádiz en España y América, 1812, Valencia, Albatros, 2013: 159-178.

Flores Galindo, Alberto, Buscando un Inca: identidad y utopía en los Andes, Lima, Sur Casa de Estudios del Socialismo, 2015 [1986].

Fuentes, Manuel Atanasio (ed.), Memorias de los vireyes que han gobernado el Perú durante el tiempo del coloniaje español, t. V, Lima, Librería Central de Felipe Bailly, 1859.

Guardia, Sara Beatriz, Mujeres peruanas. El otro lado de la Historia, Lima, Librería Editorial Minerva, 2002 [1985].

Guardia, Sara Beatriz, "Micaela Bastidas y las heroínas de la Independencia del Perú", Izaskun Álvarez Cuartero y Julio Sánchez Gómez (eds.), Visiones y revisiones de la independencia americana. Subalternidad e Independencias, Salamanca, Universidad de Salamanca, 2012: 153-174.

Guardia, Sara Beatriz (ed.), Micaela Bastidas, Lima, Edición del autor, 2019.

Gullón Abao, Alberto José, La frontera del Chaco en la gobernación del Tucumán (1750-1810), Cádiz, Universidad de Cádiz, 1993.

Gutiérrez Escudero, Antonio, «Tupac Amaru II, sol vencido: ¿el primer precursor de la emancipación?», Araucaria, 15 (Sevilla, 2006): 205-223.

Humboldt, Alejandro de, Ensayo político sobre la Nueva España, t. I, París, Jules Renouard, 1827 [1811].

Koechlin Febres, Eric, Guía del proceso emancipador (1780-1866), Lima, Fondo Editorial del Congreso del Perú, 2019.

Krebs, Ricardo y Gazmuri, Cristián (eds.), La Revolución Francesa y Chile, Santiago de Chile, Editorial Universitaria, 1990.

Lewin, Boleslao, La rebelión de Tupac Amaru y los orígenes de la emancipación americana, Buenos Aires, Librería Hachette, 1957. 
Lewin, Boleslao, "Resonancia de la Rebelión de Tupac Amaru en América y Europa", Actas del Coloquio Internacional: "Tupac Amaru y su tiempo”, Lima, Comisión Nacional del Bicentenario de la Rebelión Emancipadora de Tupac Amaru, 1982: 355-377.

Loayza, Francisco A. (ed.), Cuarenta años de cautiverio (Memorias del Inka Juan Bautista Tupac Amaru), Lima, Editorial Domingo Miranda, 1941.

Loayza, Francisco A. (ed.), Mártires y heroínas (Documentos inéditos del año de 1780 a 1782), Lima, Talleres Tipográficos de Domingo Miranda, 1945.

Loayza, Francisco A. (ed.), Genealogía de Tupac Amaru, Lima, Librería e Imprenta D. Miranda, 1946.

Lorandi, Ana María, Poder central, poder local. Funcionarios borbónicos en el Tucumán colonial. Un estudio de antropología política, Buenos Aires, Prometeo Libros, 2008.

Majluf, Natalia, "De la rebelión al museo: Genealogías y retratos de los incas, 17811900", Thomas Cummins, Gabriela Ramos, Elena Phipps, Juan Carlos Estensoro, Luis Eduardo Wuffarden y Natalia Majluf (eds.), Los incas, reyes del Perú, Lima, Banco de Crédito, 2005: 253-319.

Martín Ruiz, Enrique, Pazzis Pi Corrales, Magdalena de y Gimena, José Antonio, Los presidios españoles norteafricanos en el siglo XVIII, Madrid, Ministerio de Defensa, 2016.

Martín Sánchez, Juan, La revolución peruana: ideología y práctica política de un gobierno militar 1968-1975, Sevilla, CSIC-Universidad de Sevilla-Diputación de Sevilla, 2002.

Melgar Bao, Ricardo, "El primer exilio y la Independencia: entre categorías y nativos americanos", Carlos Sanhueza y Javier Pinedo (eds.), La patria interrumpida. Latinoamericanos en el exilio. Siglos XVIII-XX, Santiago de Chile, LOM Ediciones-Universidad de Talca, 2010: 13-34.

Moreno Bazaes, Daniel, "'Si se hiciera lo de acá se extinguiría en todas partes': Conflictos, tensiones y autoridad: la acción de la justicia frente a la amenaza de la viruela en la frontera sur de Chile, 1785", Fronteras de la Historia, 19/2 (Bogotá, 2014): 38-68.

Moreno Cebrián, Alfredo, Túpac Amaru. El cacique inca que rebeló los Andes, Madrid, Anaya, 1989.

Olivia de Coll, Josefina, La resistencia indígena ante la conquista, Madrid, Siglo XXI, 1991.

O'Phelan Godoy, Scarlett, Un siglo de rebeliones anticoloniales. Perú y Bolivia 17001783, Cuzco, CBC, 1988.

O'Phelan Godoy, Scarlett, La gran rebelión de los Andes. De Tupac Amaru a Tupac Catari, Cuzco, CBC, 1995. 
O'Phelan Godoy, Scarlett, "La construcción del miedo a la plebe en el siglo XVIII a través de las rebeliones sociales", Claudia Rosas Lauro (ed.), El miedo en el Perú. Siglos XVI al XX, Lima, PUCP, 2005: 123-138.

O’Phelan Godoy, Scarlett, “¿Indios nobles o mestizos reales? Memoriales, legitimidad y liderazgo entre la Colonia y la Independencia", Ramón Mujica Pinilla, David A. Brading, Scarlett O'Phelan Godoy, David Cahill, Luis Eduardo Wuffarden Revilla, Teresa Gisbert de Mesa, Natalia Majluf, Víctor Manuel Peralta Ruiz y Charles Frederick Walker (eds.), Visión y símbolos del virreinato criollo a la república peruana, Lima, Banco de Crédito, 2006: 43-83.

O'Phelan Godoy, Scarlett, Mestizos reales en el virreinato del Perú: indios nobles, caciques y capitanes de mita, Lima, Fondo Editorial del Congreso del Perú, 2013.

Palma, Ricardo, Tradiciones peruanas completas, Madrid, Aguilar, 1961.

Rodas, Apolonio de, Argonáuticas, Madrid, Akal, 1991.

Roel Pineda, Virgilio, Historia general del Perú. La independencia, Lima, Editorial Gráfica Labor, 1988.

Rosas Lauro, Claudia, "El miedo a la revolución. Rumores y temores desatados por la Revolución Francesa en el Perú, 1790-1800", Claudia Rosas Lauro (ed.), El miedo en el Perú. Siglos XVI al XX, Lima, PUCP, 2005: 139-166.

Rosas Lauro, Claudia, Del trono a la guillotina. El impacto de la revolución Francesa en el Perú (1789-1808), Lima, IFEA, 2006.

Serulnikov, Sergio, Conflictos sociales e insurrección en el mundo colonial andino. El norte de Potosí en el siglo XVIII, Buenos Aires, FCE, 2006.

Serulnikov, Sergio, "La imaginación política andina en el siglo XVIII", Cristóbal Aljovín de Losada y Nils Jacobsen (eds.), Cultura Politica en los Andes (17501950), Lima, UNMSM-IFEA, 2007: 383-410.

Serulnikov, Sergio, Revolución en los Andes. La era de Tupac Amaru, Buenos Aires, Editorial Sudamericana, 2010.

Serulnikov, Sergio, "La insurrección tupamarista. Historias e historiografías", José María Portillo Valdés y Roberto Breña (coords.), El mundo atlántico y la modernidad iberoamericana, 1750-1850, México D. F., Espejo de obsidiana, 2012, vol. 1: 251-264.

Solís, Ramón, El Cádiz de las Cortes. La vida en la ciudad en los años 1810 a 1813, Madrid, Alianza Editorial, 1969.

Stoetzer, Otto Carlos, "Los países del Plata (Argentina, Paraguay, Uruguay) y Chile", Roberto M. Maniquis, Óscar R. Martí y Joseph Pérez (eds.), La Revolución Francesa y el mundo ibérico, Madrid, Turner, 1989: 327-465.

Szemiński, Jan, “¿Por qué matar españoles? Nuevas perspectivas sobre la ideología andina de la insurrección en el siglo XVIII", en Steve Stern (comp.) Resistencia, 
rebelión y conciencia campesina en los Andes. Siglos XVIII al XX, Lima, Instituto de Estudios Peruanos, 1990: 164-185.

Tamayo Herrera, José (ed.), Oración fúnebre de Tupac Amaru; publicada por Melchor Equazini, Buenos Ayres, Imprenta del Sol, 1816 [Lima, BNP, 1981].

Thomson, Sinclair, Cuando sólo reinasen los indios. La política aymara en la era de la insurgencia, La Paz, Muela del Diablo-Aruwiyiri, 2006.

Ulloa, Antonio de, Viaje a la América meridional, t. II, Madrid, Historia 16, 1990 [1748].

Vaca de Osma, José Antonio, Carlos III, Madrid, Rialp, 2005.

Valcárcel, Carlos Daniel, Túpac Amaru, el revolucionario, Lima, Moncloa-Campodónico, 1970.

Valcárcel, Carlos Daniel (ed.), Colección Documental de la Independencia del Perú. La rebelión de Tupac Amaru, t. II, vol. 2º, Lima, Comisión Nacional del Sesquicentenario de la Independencia del Perú, 1971.

Valcárcel, Carlos Daniel (ed.), Colección Documental de la Independencia del Perú. La rebelión de Tupac Amaru, t. II, vol. $3^{\circ}$, Lima, Comisión Nacional del Sesquicentenario de la Independencia del Perú, 1972.

Valcárcel, Carlos Daniel, La rebelión de Túpac Amaru, México DF, FCE, 1996 [1947].

Valle de Siles, María Eugenia del, Historia de la rebelión de Tupac Catari, 17811782, La Paz, Editorial Don Bosco, 1990.

Vergara Collazos, Antonio, Los Tupac Amaru en Europa, 1780-1980, Barcelona, ATE, 1981.

Villalobos, Sergio, "Un documento sobre la rebelión de Tupac Amaru en Tarapacá", Actas del Coloquio Internacional: "Tupac Amaru y su tiempo", Lima, Comisión Nacional del Bicentenario de la Rebelión Emancipadora de Tupac Amaru, 1982: 651-662.

Villanueva Urteaga, Horacio, "Pinturas de la rebelión de 1780", Actas del Coloquio Internacional: “Tupac Amaru y su tiempo", Lima, Comisión Nacional del Bicentenario de la Rebelión Emancipadora de Tupac Amaru, 1982: 663-665.

Walker, Charles F., De Tupac Amaru a Gamarra. Cusco y la formación del Perú republicano 1780-1840, Cuzco, CBC, 1999.

Walker, Charles F., La rebelión de Tupac Amaru, Lima, IEP, 2015.

Fecha de recepción: 22 de enero de 2018.

Fecha de envío de las modificaciones: 7 de junio de 2018 .

Fecha de aceptación: 26 de julio de 2018. 


\section{The American repercussions of the Tupac Amaru rebellion and its influence in Spain: a forgotten episode}

The space-time coordinates of the rebel movement headed by Tupac Amaru II between 1780 and 1781 went further than its repercussions in Peru and Upper Peru. This article analyses the arduous journey undertaken by Tupamarista prisoners, both in Chile and Spain. In the Chilean case, we will study the fear aroused among local authorities by the temporary presence of these prisoners, especially as a possible source of social contagion. Regarding the few Tupamarista prisoners who survived shipwreck and disease before finally arriving in Spain, we will focus on their personal trajectories in Spanish jails in Africa.

Key words: Peru; Chile; Spain; Tupac Amaru II; exile; shipwreck. 